\title{
OPTIMIZATION OF B-SERIES PROPELLER DESIGN AS KCR 60 PROPULSOR TO ACHIEVE OPTIMAL PERFORMANCE USING MATHEMATICAL MODEL
}

\author{
Akhmat Nuryadin, Abdul Rahman, Cahyanto. \\ Indonesian Naval Technology College, \\ Bumimoro-Morokrembangan, Surabaya 60187, Indonesia
}

\begin{abstract}
The process of designing a propeller as a ship propulsor is an important step to produce a propeller that has the ability to achieve the desired target speed of the ship. Propeller optimization is an effort to produce a propeller design with optimal capabilities. This propeller design uses a B-series propeller where this propeller is commonly used as ship propulsor. Optimization steps to find the optimal propeller, namely: determining the objective function, determining the decision variable, and determining the constraint variable. The objective function of this optimization is to determine the Advanced-optimal (J-opt) coefficient value for the propeller. The $\mathrm{J}$-opt coefficient must have a value greater than the $\mathrm{J}$-Design coefficient $(\mathrm{J}-\mathrm{d})$ value and the smallest possible value (minimization function). For decision variables include picth diameter ratio $(P / D)$ and Blade area ratio $(A e$ $/ A o)$ and number of leaves (Z). While the constraint variables are: the pitch diameter ratio value of the $B$-series propeller $(0.5 \leq P / D \leq 1.4)$, the blade area ratio $B$-series $(0.3 \leq A e / A o \leq 1,05)$ as well as the number of blade $(2 \leq Z \leq 7)$. From the calculation results of the optimization of the $B$-series propeller design for the KCR 60 , the optimum value is different for each blade. the propeller with the number of blade $2(Z=2)$ obtained the optimum propeller with the value of $\mathrm{J}$-opt $=0.77098733, A e / A o=0.3, P / D=1.13162337, K_{T}=0.165632781,10 K_{Q}=0$, 27546033 and efficiency $=0.73198988$. Popeller with number of blades $3(Z=3)$ obtained optimum propeller with J-opt value $=0.77755594, \quad A e / A 0=0.3, \quad P / D=1.06370107, \quad K_{T}=0.168069763, \quad 10 K_{Q}=0.28984068$ and efficiency $=0.70590799$. Propeller with number of blades $4(Z=4)$ obtained optimum propeller with $J$-opt value $=0.78478688, \quad A e / A o=0.45954773, \quad P / D=1.03798312, \quad K t=0.172147709, \quad 10 K q=0.3091063$ and efficiency $=0.67797119$. Propeller with blades number $5(Z=5)$ obtained optimum propeller with J-opt value $=0.78575616, \quad A e / A 0=0.65607164, \quad P / D=1.02716571, \quad K_{T}=0.174099168, \quad 10 K_{Q}=0.31376705$ and efficiency $=0.67547177$. Propeller with blades number $6 \quad(z=6)$ obtained optimum propeller with $\mathrm{J}$-opt value $=0.78867357, A e / A o=0.71124343, P / D=1.0185055, K_{T}=0.176525247,10 K_{Q}=0.32215257$ and efficiency $=0.66705719$. Propeller with number of blades $7(Z=7)$ obtained optimum propeller with $\mathrm{J}$-opt value $=0.7949898$, $A e / A o=0.69772623, P / D=1.01780081, K_{T}=0.181054792, K_{Q}=0.34011349$, and efficiency $=0.64804328$.
\end{abstract}

Keywords : KCR, Optimization, Wageningen B-series.

\section{INTRODUCTION.}

One of the most important aspects in the shipbuilding process is the propulsion system planning. In the propulsion system planning there is a propeller design plan. Propeller is a vital part that must be planned properly so that the thrust needed by the ship is met so that the desired accuracy can be achieved. To get the optimal propeller, the propeller design process must be carried out with good calculations.

The problem faced in making KCR 60 phase I $(628,629,630)$ is that the maximum speed of 28 knots has not been achieved in accordance with the provisions of the procurement contract. Given these problems, it is possible that there was a mistake in determining the design of the propeller to be used as a KCR 60 propulsor. Error in engine propeller matching and errors in designing the ship's hull itself which results in relatively larger vessel resistance (Leksono, Marine Military Feasibility Workshop, 2015.
Propeller used in this calculation is wageningen B-series based propeller. The Bseries Propeller has a Pitch diameter value of 0.5 $1.4(0.5 \leq P / D \leq 1.4)$, Blade area ratio of $0.3-1.05$ $(0.3 \leq \mathrm{Ae} / \mathrm{Ao} \leq 1,05)$, and the number of blades $2-7$ $(2 \leq Z \leq 7)$. The optimum propeller is a propeller with sufficient thrust value, lowest torque and highest efficiency.

The process used to get the optimal propeller is by doing propeller optimization. The value of thrust coefficient $\left(\mathrm{K}_{\mathrm{T}}\right)$ and torque coefficient $\left(\mathrm{k}_{\mathrm{Q}}\right)$ and efficiency are obtained from the results of the $B$-series polynomials. To simplify the optimization process, the calculation is done with the help of the solver program contained in Excel software.

The purpose of this research is to get a propeller design with optimum performance. So that with optimum capability it is expected that the propeller is able to produce thrust as needed and can achieve the desired speed target. 


\section{MATERIALS AND METHODS}

2.1 MATERIAL.

a. Planning of Ship Propulsion System

Leksono (2015) defines that in its operations at sea, a ship must have the ability to maintain official speed (Vs) as planned. This means that, the ship must have a propulsion system design (drive) that can overcome the overall drag forces (total resistance) that occur to meet the service speed standards. The Ship Propulsion System consists of three main components, including: the main engine, transmission system, and propulsor.

Errors in design, will bring a very large 'consequence' to the conditions as follows; not achieving the speed of planned ship service, Inefficient fuel oil consumption, decrease in the economic value of the ship, effect on the level of vibration that occurs on the ship's body, etc

\section{b. Characteristics of Ship Propellers}

Each type of ship propeller has different performance curve characteristics (Lewis E. V., 1988), that is:

$$
\begin{aligned}
& J=\frac{V_{a}}{n \times D} \\
& K_{T}=\frac{T_{\text {Prop }}}{\rho \times n^{2} \times D^{4}} \\
& K_{Q}=\frac{Q_{\text {Prop }}}{\rho \times \mathrm{n}^{2} \times D^{5}}
\end{aligned}
$$

where:

$$
\begin{array}{lll}
\mathrm{J} & : \text { Advanced coefficient } \\
\mathrm{Va} & : \text { The advanced speed }(\mathrm{m} / \mathrm{s}) \\
\mathrm{KT} & : & \text { The thrust coefficient of a propeller } \\
\mathrm{KQ} & : & \text { The propeller torque coefficient } \\
\mathrm{T} & : \text { PropellerThrust }(\mathrm{kN}) \\
\mathrm{Q} & : \text { Propeller Torque }(\mathrm{kN})
\end{array}
$$

\section{c. Polynomial B-series Model}

The B-series polynomial model is a representation of the open water propeller diagram. This polynomial is used to determine the value of the coefficient of thrust $(\mathrm{KT})$, Torque Coefficient (KQ) and efficiency $(\eta)$ with the number of blades 2 to 7 (Ossanen, 1975). This polynomial is obtained from multiple regression analysis with the following formula:

$$
\begin{aligned}
K_{T} & =\sum_{s, t, u, v} C_{s, t, u, v}^{T}(J)^{s}\left(\frac{P}{D}\right)^{t}\left(\frac{A e}{A o}\right)^{u}(Z)^{v} \\
K_{Q} & =\sum_{s, t, u, v} C_{s, t, u, v}^{T}(J)^{s}\left(\frac{P}{D}\right)^{t}\left(\frac{A e}{A o}\right)^{u}(Z)^{v}
\end{aligned}
$$

For reynolds number greater than $2 \times 10^{6}$ the open water propeller characteristics should be correted. The corrections are:

$$
\Delta K_{T}\left(R e, J, \frac{P}{D}, \frac{A e}{A o}, Z\right)
$$

$$
\Delta K_{Q}\left(R e, J, \frac{P}{D}, \frac{A e}{A o}, Z\right)
$$

\section{d. Optimization}

Optimization is a process to achieve ideal or optimal results (effective value that can be achieved). In the discipline of mathematics optimization refers to the study of problems that try to find the minimum or maximum value of a real function. Some classifications in optimization are:

- Linear vs non linear problem

- Constrained vs unconstrained problem

- One variable vs n-variable problem

- Continuous vs discrete function

- Search vs gradient methods.

\section{e. Program Solver (Excel)}

Solver is an additional program for Microsoft Excel that can be used to analyze and find the optimal value (maximum or minimum). To get the value of the objective function and the decision variable is done by determining the values of the boundary variables. With this solver program optimization calculations can be completed.

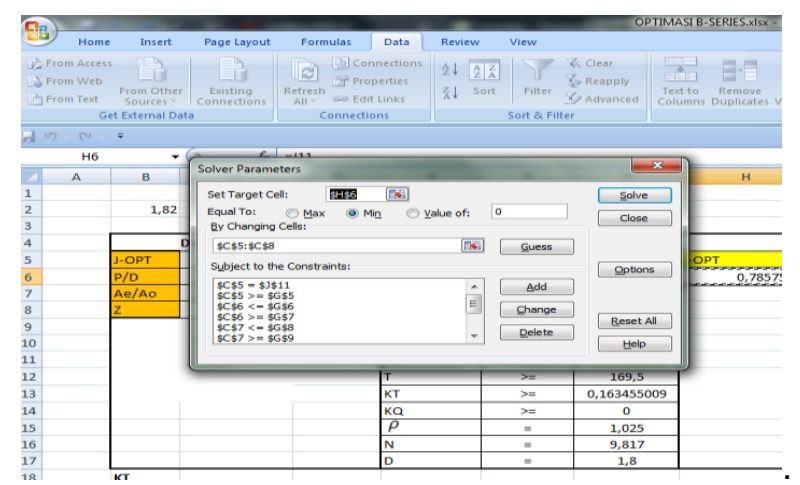

Fig. 1. Solver program

\section{f. MARIN DESPPC and PREDFDS Program}

Numerical calculations using the MARIN DESPPC and PREDFDS program require some data: main ship size data, hydrostatic data, propeller data, and installed shafts and position, steering leaf data along with installation location.

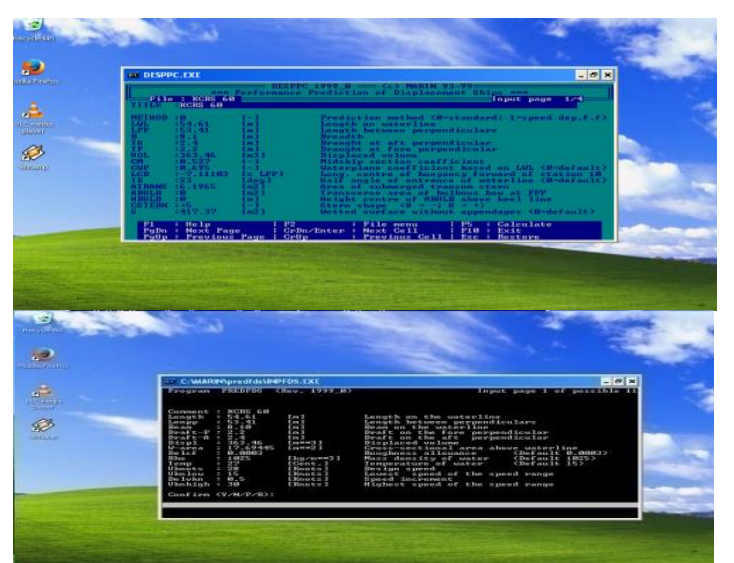

Fig. 2. MARIN DESPPC and PREDFDS Program Display 


\subsection{METHODS.}

a. Flowchart of Research

The research process carried out can be seen in Figure 3.

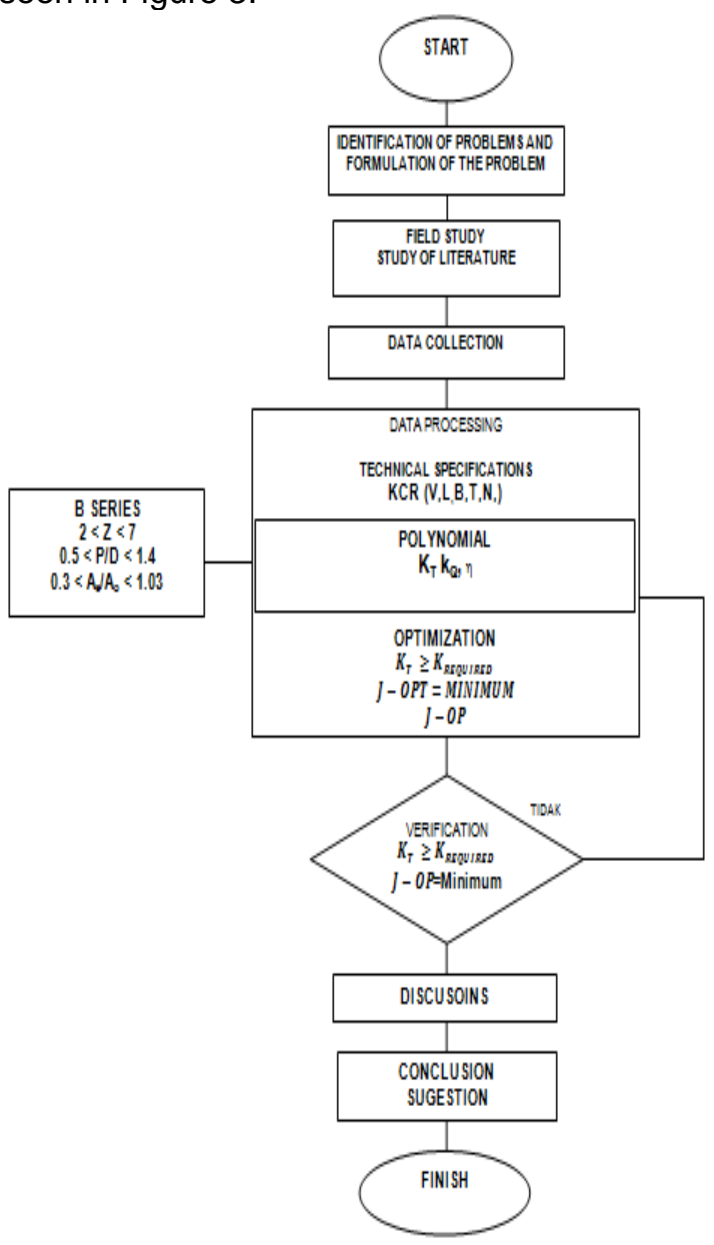

Fig. 3. Flowchart of research

b. Data Processing and Discussion.

Data analysis is adjusted to the needs of the KCR 60 technical specifications. Propeller calculations use a polynomial model and optimization estimates use the Excel Solver program.

\section{RESULT AND DISCUSS}

\subsection{Optimization To Determine Propeller} Design

The steps used in performing this optimization calculation are:

a. Determine the value of the objective function (Objective Function).

b. Determine the value of the decision variable (Decision Variable) of the propeller.

c. Determine the values of constraints (constraints) of the propeller and prerequisites of the ship.

d. Using the polynomial model to determine the value of $\mathrm{K}_{\mathrm{T}}$ and $\mathrm{K}_{\mathrm{Q}}$ propeller.

The objective function of calculating the design of this propeller design is to minimize the value of the $\mathrm{J}$-Optimal coefficient $\left(\mathrm{J}_{\mathrm{Opt}}\right)$. $\mathrm{J}_{\mathrm{Opt}}$ value is the value of the coefficient $\mathrm{J}$ at the intersection of $\mathrm{K}_{\mathrm{Q}}$ with $\mathrm{J}^{5}$. The value of the $\mathrm{J}_{\mathrm{Opt}}$ value must be greater than the J-Design $\left(J_{D}\right)$ coefficient value. The equation and inequality of the objective function are:

$$
\begin{gathered}
10 K Q=J_{O P T}{ }^{5} \\
J_{O P T}>J_{D}
\end{gathered}
$$

The decision variable in this calculation is the values of the propeller size and the $J_{O P T}$ value to be determined. The decision variables include: J-Optimal Coefficient (JOPT), Pitch diameter ratio $(P / D)$, Blade Area Ratio (AE/AO), and Number of propeller blades $(Z)$. The value of this variable is the input data to determine the value of the thrust coefficient $\left(\mathrm{K}_{\mathrm{T}}\right)$, torque coefficient $\left(\mathrm{K}_{\mathrm{Q}}\right)$, and efficiency $(\eta)$.

The decision variable in this calculation is the values of the propeller size and the JOPT value to be determined. The decision variables include: J-Optimal Coefficient (JOPT), Pitch diameter ratio $(P / D)$, Blade Area Ratio (AE / $A O)$, and Number of propeller leaves (Z). The value of this variable is the input data to determine the value of the thrust coefficient (KT), torque coefficient $(K Q)$, and efficiency $(\eta)$.

Limitation / constraint variables are constraints that must be met. Equations and inequality of the limitation / constraint variables are:

$$
\begin{gathered}
J_{D}, J_{O P T}>0 \\
J_{O P T}>J_{D} \\
K_{T}, K_{Q}>0 \\
0,5 \leq \frac{P}{D} \leq 1,4 \\
0,3 \leq \frac{A_{E}}{A_{O}} \leq 1,05 \\
2 \leq Z \leq 7
\end{gathered}
$$

\begin{tabular}{|c|c|c|c|c|c|c|c|}
\hline \multicolumn{8}{|c|}{ SELECTED PROPELLERB BSERESES } \\
\hline NO & TPPE & AEAO & PD & JDESAN & J.OPT & KTR & KT:PROP 10KQPRPOP EFF,PROP \\
\hline 1 & B.2 & 0,3 & 1,13162337 & 0,7645 & 0,77098733 & 0,163455 & $0,165632800,0,27540030,0,7319899$ \\
\hline 2 & B.3 & 0,3 & 1,06370107 & 0,7645 & 0,77755594 & 0,163455 & 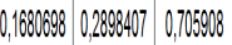 \\
\hline 3 & B.4 & 0,5556477 & 1,03798312 & 0,7045 & 0,78478688 & 0,163455 & $0,17214770,03910630,0779912$ \\
\hline 4 & B.5 & 0,5600716 & 1,02716571 & 0,7645 & 0,785756016 & 0,163455 & $0,1740992 \quad 0,31376710,06754718$ \\
\hline 5 & $B .6$ & 0,1112434 & 1,0185055 & 0,7645 & 0,78867357 & 0,163455 & $0,1765252-0,32215260,0,060572$ \\
\hline 6 & $B .7$ & 0.6977262 & 1,01780081 & 0,7645 & 0,7999898 & 0,163455 & $0,18105480,034011350,0,0404333$ \\
\hline
\end{tabular}

3.2 Optimization calculation to determine the Optimum Propeller in each of Blade

The results of optimization calculations using the help of the Excel Solver program are:

Table. 1. Propeller optimization calculation results 
From the table above it can be seen that in each number of leaves, there is only 1 (one) propeller with the most optimum ability. To use propeller as propulsor, the owner of the ship / shipyard has different tastes in choosing the number of blades.

\section{CONCLUSION}

From the results of the analysis and calculations that have been made, conclusions can be drawn as follows:

a. By using optimization techniques can be obtained optimum propeller in each number of blades. Propeller with 2 (two) blades has the highest efficiency.

b. For KCR 60 ships can use B-series propellers with 4 blade $(Z=4)$ optimum propeller is obtained with J-opt value $=0.78478688, \mathrm{Ae} /$ $\mathrm{Ao}=0.45954773, \quad \mathrm{P} /=1.03798312, \quad \mathrm{Kt}=$ $0.172147709, \mathrm{Kq}=0.3091063$ and efficiency $=$ 0.67797119 .

c. The B-series propeller performance can be applied as a KCR $60 \mathrm{M}$ propulsor to reach speeds of 28 knots on draft $2.6 \mathrm{~m}$ (full load).

\section{REFERENCES}

Barras, C. (2004). Ship Design and Performance for Masters and mates. Oxford: Elsevier.

Leksono, S. (2015). Marine Military Feasibility Workshop. Surabaya: UPT BPPH.

Leksono, S. (2000). Propeller Synchronization with Master Machines on Fish Ships to Improve Efficiency and Performance. Surabaya: ITS Shipping Polytechnic.
Leksono, S. (2000). Synchronizing Propellers with Main Engines on Fish Ships to Improve Efficiency and Performance. ITS Shipping Polytechnic Paper.

Lewis, E. V. (1988). Principles of Naval Architecture Second Revision. New Jersey: TheSociety of Naval Architecs and Marine Engineers.

Lewis, E. V. (1988). Principles of Naval Architecture Second Revision. New Jersey: The Society of Naval Architecs and Marine Engineers.

Martin.R. (2016). Optimization of Scheduling for Installation of Electrical and Navkom Installation in 60-missile Fast Ship Manufacturing with CPM Method. Proceedings of the STTAL Postgraduate National Seminar (pp. 1-18). Surabaya: STTAL.

Ossanen, M. a. (1975). Further ComputerAnalyzed Data of the Wageningen B-Screw Series. International Shipbuilding Vol.22.No.251 .

Setyo. (2015).Sumartojo, I. (2006). Ship Building Theory I. Surabaya: Kobangdikal.

Susanto, A. D. (2017). Analysis of the Propulsion System Toward The Speed Reduction of Vessels Type PC-43. International Journal of Engineering Research and Applications (IJERA) , 7 (4), 08-15.

Sv.Aa.Harvald. (1983). Resistant and Propulsion of Ships. New York: Wiley. 